\title{
New Thoughts on Promoting the Development of Jingzhou Agricultural Tourism by Characteristic Agriculture
}

\author{
Ming Luo ${ }^{1}$, Tong Tong1, Fan Sima ${ }^{2}$ \\ ${ }^{1}$ Department of Economics and Law, Yangtze University College of Arts and Science, Jingzhou, China \\ ${ }^{2}$ Aerospace Nanhu Electronic Information Technology Co. Ltd., Jingzhou, China \\ Email: 18043258@qq.com
}

How to cite this paper: Luo, M., Tong, T., \& Sima, F. (2020). New Thoughts on Promoting the Development of Jingzhou Agricultural Tourism by Characteristic Agriculture. Open Journal of Social Sciences, 8, 325-335.

https://doi.org/10.4236/jss.2020.84023

Received: September 10, 2019

Accepted: April 19, 2020

Published: April 22, 2020

Copyright $\odot 2020$ by author(s) and Scientific Research Publishing Inc. This work is licensed under the Creative Commons Attribution International License (CC BY 4.0). http://creativecommons.org/licenses/by/4.0/

\begin{abstract}
Industrial prosperity is the focus of rural revitalization. As a traditional agricultural province, Hubei Province has a prominent position in the country. Promoting the development of characteristic agriculture and achieving industrial prosperity are the only way for Hubei to implement the rural revitalization strategy. Taking Jingzhou City as an example, through analyzing the status quo of characteristic agriculture such as Sanhuhuangtao and Buhe grape, it studies its opportunities and existing problems, and puts forward the characteristics and advantages of agricultural industry, paying attention to top-level planning, integration of three industries, and tradition. Measures such as the combination of cultural resources and the cultivation of market entities, rely on "Qingshan Green Water" to vigorously develop the tourism and tourism integration industry and promote the tourism development of Jingzhou.
\end{abstract}

\section{Keywords}

Characteristic Agriculture, Agricultural and Touristic Integration, Jingzhou

\section{Introduction}

President Xi first proposed the implementation of the rural revitalization strategy in the report of the 19th National Congress of the Communist Party of China. To implement the rural revitalization strategy and promote the integration of urban and rural development, it is necessary to define the function and positioning of the village as the premise and foundation. Through the integration of agricultural tourism, this strategy can be promoted quickly and effectively. Since then, the integration of agricultural tourism has entered a new stage of develop- 
ment in China. This is the general trend of the development of the three rural areas, and it is also the direction of urban and rural development.

In recent years, the integration of agriculture and tourism in China has developed rapidly, but there are still some problems in the development process. The overexploitation of primary resources makes it difficult to protect and inherit them. The integration of rural tourism is too simple for the surface development and low economic efficiency. This article takes Jingzhou characteristic agriculture as the research object, through carrying on the comprehensive thorough analysis to Jingzhou characteristic agriculture present situation, the question, and how promotes the agriculture and tourism fusion through Jingzhou characteristic agriculture development to put forward the corresponding countermeasure suggestion. It is hoped that the integrated development of agriculture and tourism will eventually effectively promote the construction of rural infrastructure, improve the level of economic and social development, attract farmers to return home to start businesses and find jobs, increase farmers' economic income, promote the development of characteristic agriculture, protect and inherit traditional culture.

\section{Jingzhou City Overview}

Jingzhou is located in the middle reaches of the Yangtze River and the middle and south of Hubei province. It is located in the hinterland of Jianghan plain, a beautiful and fertile land with thousands of miles of fertile countryside. Jingzhou is the only city and state in the whole province that also ranks in the Yangtze river economic belt, the city cluster in the middle reaches of the Yangtze river, the Dongting lake ecological economic zone, the state-level industrial transfer demonstration zone, the state-level transformation and upgrading demonstration zone, and the state-level high-tech zone. The strategic layout of "one core, two belts and three zones" positioning Jingzhou as an important node city of "Yangtze river green economy and innovation-driven development belt" and the core city of "Jianghan plain revitalization and development demonstration zone". Jingzhou has formed six pillar industries and 11 provincial key industrial clusters. Jingzhou is the province's advantage agricultural resources core area, the national important agricultural products comprehensive production base. Agriculture is the most prominent advantage of Jingzhou. We will promote the development of Jingzhou high-tech zone into a "green valley of China", lead the development of modern agriculture in the city, foster backbone leading enterprises, and expand the new type of agricultural business. As a national important comprehensive agricultural production base, the annual grain output accounts for about $1 \%$ of the country. Jingzhou high-tech zone is the third national high-tech zone and the first national high-tech zone featuring agriculture in HuBei province. It has been approved as the national agricultural science and technology park, the national agricultural science and technology innovation and integration demonstration base, the national modern agricultural science and technology demonstration zone, and the modern agricultural science and 
technology demonstration zone in Jianghan plain.

\subsection{General Situation of Huangtao Industry in Jingzhou City}

Sanhu farm, Jiangling county, Jingzhou city, has a planting area of more than $10,000 \mathrm{mu}$ and a production of more than 6000 tons, with a sales volume of more than 80 million yuan. The average income per mu is $3500-5000$ yuan, which is $8-10$ times of the income from field crop cultivation. In 2017, Sanhu farm set up a special working class for leaders of the agricultural and tourism integration headquarters, focusing on promoting the integration of agriculture and tourism, innovating tourism formats, and successfully holding the "peach blossom festival" and "yellow peach festival". Each sub-field has built a demonstration base of $100 \mathrm{mu}$ fine garden, and gradually formed the model of "fine garden + farmhouse". Sanhu farm Huangtao boutique garden won "Hubei province leisure agriculture demonstration point", Sanhu farm new brigade won "national one village one product demonstration village". Meanwhile, Sanhu farm makes full use of the high forest coverage and good natural ecological environment to promote the construction of "ecological characteristic town". The standard development of yellow peach industry and ecological construction are carried out simultaneously. Such a set of data is sufficient to illustrate the integration effect of agriculture and tourism in Sanhu administrative district (farm): in 2017, the annual output value of industry and agriculture reached 1.084 billion yuan, the gross national product reached 369 million yuan, the per capita disposable income reached 20,500 yuan, and the tax revenue reached 7.35 million yuan, with year-on-year growth of $14.7 \%, 12.5 \%, 16.5 \%$ and $25 \%$ respectively, and the fixed asset investment reached 237 million yuan. Zhu Shao-Bo (2017) believes that the Sanhu farm will focus on yellow peach industry, supplemented by ratooning rice, selenium-rich rice and shrimp rice industry, develop regional tourism, strengthen ecological environmental protection, build beautiful countryside, and promote the development of tourism and sightseeing agriculture.

\subsection{General Situation of the Grape Industry in Jingzhou City}

The development of the grape industry in the public security county, after 30 years of exploration, from scratch, from superior to superior, from superior to strong, has achieved the income of the masses to get rich, the current grape planting area of the county is 110,000 acres, with an annual output value of more than 1 billion yuan. Buhe Town adheres to the combination of town reconstruction and expansion, rationally allocates various elements, and compiles the conceptual planning and control details of the grape town. The exhibition area featuring the core areas of the tourist reception center, the special cultural district and the education and cultivation, the grape growing and winery, the product processing plant, etc., the industrial area represented by the construction of the grape industry park, and the farming. The four major areas of leisure, education, training and recreation, form a characteristic style of rural life and a green coordinated and sustainable development pattern, focusing on building planting, 
warehousing, processing, research and development, sightseeing, leisure and recreation. The grape industry park is integrated into the whole industry chain. By highlighting the construction of "variety improvement, quality improvement, brand promotion", the public security grape won the national geographical protection mark, "Jingliangtian" and "Jingqiuyuan" won the national famous trademark brand, and "Jingliangtian" grape won the title of Hubei Famous Agricultural Product. The transformation mode of Buhe Town was adopted, and the model of "company + cooperative + farmer" was adopted to realize the close cooperation relationship of land transfer, labor contracting and net profit sharing. Pay close attention to industrial upgrading, adhere to the three industries in the development of the grape industry, one production and one after another, industrial integration and development. Relying on the grape farm sightseeing corridor of the ecological farm and the Beizha Water Conservancy Scenic Area to develop the whole area tourism, the whole day of the grape ripening period can reach 5000 visitors.

\section{Opportunities for the Integration of Agriculture and Tourism in Jingzhou}

The development of modern agriculture is the center of agricultural industry construction in Jingzhou City. The integration of agriculture and tourism is a bridge to promote the construction of characteristic towns in Jingzhou. The construction of characteristic agricultural industrial towns is a major issue in the development of Jingzhou's agriculture. So far, the construction of a town with a characteristic agricultural character in Jingzhou has just begun. During the 12th Five-Year Plan period, Jingzhou modern agriculture has developed by leaps and bounds, providing a good foundation for the integration of Jingzhou agricultural tourism.

The tourism resources of Jingzhou are very rich, the culture of chu, the culture of The Three Kingdoms, the culture of water control and the "three cultures" are profound, the cultural sites are full of beautiful things in eyes, and the non-material culture is colorful. On March 31, 2020, the platform of "Learning Power "came to the ancient city of Jingzhou in cooperation with "Hubei Yangtze river cloud" and "Jingzhou on the cloud". The hour-long event has attracted a lot of attention from netizens, with up to 9 million people streaming online. The central and local media have continuously focused on the historical and cultural tourism area of the ancient city of Jingzhou. Through live broadcast and news reports, people all over the country have deeply felt the beautiful scenery and profound historical and cultural heritage of the ancient city of Jingzhou, which has greatly enhanced the popularity and influence of the scenic spot of the ancient city of Jingzhou.

The major strategic deployment of the 19th National Congress of the Communist Party of China and the Fifth Plenary Session of the 18th Central Committee on "Developing Agricultural Modernization and Accelerating the Transformation of Agricultural Development Mode" pointed out the overall direction 
for agricultural and rural economic development. The "One Belt and One Road", the Yangtze River Economic Belt, the Yangtze River Midstream City Group and other major national strategic implementations, as well as the construction of the National Modern Agricultural Science and Technology Demonstration Zone in Jingzhou, provide a greater development space for Jingzhou Modern Agriculture to optimize its industrial structure, regional layout and opening up and cooperation. The "two-type" social construction, the construction of characteristic towns and the "synchronization of the four modernizations" have provided a powerful driving force for the transformation and upgrading of agriculture and rural economic development. It will guide the development of agriculture to a low-carbon cycle and green ecology, and create a "smart agriculture". "Provides strong support." Zhao \& Liu (2018) believed that learning from the international development experience of agricultural and industrial integration of Japan, agricultural and commercial integration of the United States and agricultural and tourism integration of France would be beneficial to guiding China's practice. Jingzhou has always attached great importance to agriculture and rural economic development, adhere to the "industry nurturing agriculture and cities support rural areas" approach, provide a reliable financial security, the rule of law and protection of policy support for agriculture and rural economic development.

\section{Problems in the Development of the Integration of Agricultural Tourism in Jingzhou}

\subsection{Planning and Industrial Layout Are Not Rigorously Scientific}

In terms of planning, there is a lack of detailed research and analysis on the current status of the agricultural industry, and the disconnection between planning and the real industry is widespread. In terms of industrial layout, only consider the immediate input and output, lack of comprehensive consideration of local humanities, environment, supporting industries and other factors, cannot produce agglomeration effect, and greatly reduce the value-added benefits that can be brought about by characteristic agriculture. The variety structure of agricultural products is relatively simple, and the market competitive advantage is not strong. $90 \%$ of the farmers have fewer varieties, the harvesting period is relatively concentrated, and the cycle is short, which is not conducive to the time difference and the price of agricultural products. The sales pressure during the mature period is high, especially the storage, packaging and transportation technologies during the fruit market are not kept up. Less competitive failure to pay attention to the balance between development and protection has led to the blind development and over-exploitation of some traditional villages in development, and the destruction of residential houses in development.

\subsection{Lack of Excavation and Rational Use of Traditional Superior Resources}

Superior traditional resources are the foundation of integrated construction of agriculture and tourism. However, at present, in the process of rural construc- 
tion, only pay attention to the appearance of villages and towns renovation, demolition of the old to build new, lack of the mining and integration of traditional resources. There are many excellent cultural traditions and folk cultures in rural areas, but no effective excavation. In daily management operations, the public identity special, both managers, server, the general public, such as multiple identities, prone to extensive management, business casual, look not enough long-term problems, so that cause the backward management, service level, income, ability under adverse consequences of poor, restricted the agricultural integration development.

\subsection{The Degree of Industrial Scale Is Not High, the Degree of Industrial Integration Is Insufficient}

The equations are an exception to the prescribed specifications of this template. You will need to determine whether or not your equation should be typed using either the Times New Roman or the Symbol font (please no other font). Equations should be edited by Mathtype, not in text or graphic versions. You are suggested to use Mathtype 6.0 (or above version). Although Jingzhou has made great progress in agricultural development, it is still in the transition stage from traditional agriculture to modern agriculture in some rural areas, and small-scale and traditional extensive production mode is still continued to a large extent. Standardized and specialized production cannot meet the needs of large-scale characteristic agricultural product processing industry, and the industrial advantages of characteristic agriculture are hard to give play to. In addition, the integration of primary, secondary and tertiary industries in rural areas is not enough, young people lose interest in agriculture and young labor force decreases, which brings shock to the healthy development of agricultural industry and restricts the development of rural economy.

\subsection{Insufficient Capital Investment, Imperfect Infrastructure Facilities}

Capital problem is the most important factor restricting the development of characteristic agriculture. Unstable cash flow brings heavy pressure to agricultural enterprises. Although Jingzhou city has continuously increased its support for agricultural industry and introduced a series of supporting policies, it is difficult for agricultural production enterprises to meet the needs of production due to the relatively long return period of agricultural investment and certain uncertainties. Even the characteristic agriculture with some advantages still faces the problem of financing difficulty in the development process, which affects investors' enthusiasm for investment in agriculture.

Insufficient capital investment has led to imperfect infrastructure such as rural roads, water conservancy, living facilities, and the Internet. There is no good custody and maintenance system for the completed facilities, and the phenomenon of construction and destruction is serious. Because these safeguard measures are not in place, it has seriously affected the amplification of the benefits of 
special agricultural products and the enhancement of added value, which is a development problem facing rural areas.

\section{New Thoughts on Promoting the Development of Jingzhou Agricultural Tourism by Characteristic Agriculture}

In order to accelerate the integration of Jingzhou agricultural tourism and consolidate the results of precision poverty alleviation, through the analysis of the current situation of Jingzhou's characteristic agriculture, and put forward corresponding countermeasures and suggestions, we can achieve the goal of integrating tourism and tourism in Jingzhou City to promote the development of global tourism.

\subsection{Strengthen Planning Guidance, Do a Good Job in Top-Level Design}

On September 4, 2019, the ministry of culture and tourism released the list of the first batch of national whole-region tourism demonstration zones, which points out the direction and provides guidelines for promoting the reform and innovative development of tourism. For three consecutive years, the government work report has deployed the whole region tourism, and the whole region tourism has been promoted as a national strategy. Li Hui-Jian (2018) finds that planning and guidance are the basis for the integrated development of agriculture and tourism. Should base on the general strategy of the "industry leading, comprehensive development", the government is promoting the development of the agriculture brigade fusion "centre", from the organization and leadership, policies and measures, operation system, evaluation mechanism and so on all have clear rules, top-down, level 1 level and primary level, for at the grass-roots level has provided a broad space for development and policy support. The planning should focus on the four functions of industry, culture, tourism and community, build a pastoral complex integrating development, grasp the multiple functions of developing characteristic industries, exploring local culture, serving tourism and facilitating life, and reasonably set up projects and carriers. Planning to aim at domestic and even international first-class level, regardless of hardware, and software construction, and strive to "one village one style", multidimensional geomorphic features, construction characteristics and ecological characteristics, adhere to the ecological priority, ecological line, implements the "embedded development", on the basis of retain the original natural landscape, building and cultural background with Jingzhou characteristics of farming demonstration area brigade fusion, let the green, comfortable, relaxed become the norm in characteristic town, the formation of "one village one species, one village one scene, takes a rhyme" the happiness of the new pattern of beauty.

\subsection{Make Full Use of the Seasonal Characteristics of Agricultural Resources, Combined with Traditional Cultural Resources}

No matter which kind of agricultural resources are used to realize the integration 
and development of agriculture and tourism, we cannot avoid the seasonal characteristics of agriculture. How to make farmers have sustainable income, we must make full use of the seasonal characteristics of agricultural resources and implement diversified business ideas. For example, in addition to planting "Spring Blossom" rapeseed, golden marigold can be planted along the road. The flower is open from July to August, and the flower can refine "soft gold" natural lutein. This not only allows the growers to have an additional "autumn flower" income, but also makes the autumn of the area enjoyable, extending the time period of the local tourist season. Driven by the government and the agricultural industry, the village also needs to dig deep into the traditional cultural resources of the village. It is necessary to make good use of cultural resources, seize opportunities based on its own cultural characteristics, and borrow money to build its own cultural taste. For example, the village history and the village context can be deeply combed, and the versatility of culture should be combined with the innovation of special products, such as the lotus industry, the flower industry, the grape industry, etc., and the artistic atmosphere of traditional cultural resources and red cultural resources. Cultural quality is integrated into agricultural products to create a high value-added agricultural product industrial chain and enhance the taste of the country.

Jingzhou has a long history and profound cultural heritage. Each region has historical and cultural resources that can be excavated. Chu culture and the culture of the Three Kingdoms are famous. The agricultural products with rich characteristics are rich in resources, such as the public security grape, Sanhu Huangtao and other geographical indications and agricultural products. Zhang Guan (2019) believes that traditional culture needs to be skillfully integrated into characteristic agricultural products to create a traditional art village, has a broad space for development, and has important implications for the integration and development of Jingzhou agricultural tourism.

\subsection{Develop Agricultural Characteristic Economy and Strengthen the Cultivation of Market Players}

The cultivation of market players can effectively promote industrial development. Through the analysis of characteristic towns in Zhejiang province and Chengdu, Lu \& Xu (2019) are closely connected with local characteristic agricultural industry and historical classic industry, Yue Feng-Xia (2017) focusing on the most basic and advantageous characteristic industry. Even if the main focus on the same industry, also adhere to differential positioning, segmentation, dislocation development. For example, songyang tea incense town and west lake longwu tea town are featured by tea industry, but songyang tea incense town is featured by agricultural industrialization, scale and brand development of tea, and strengthening the integration of primary, secondary and tertiary industries. The west lake longwu tea town focuses on urban agricultural tourism and features tea industry, tea culture and tea life.

Jingzhou city can promote the integration of agriculture and tourism through 
characteristic agriculture to form characteristic towns. In addition to developing characteristic agricultural products according to local conditions, Jingzhou city can also actively create charming towns, beautiful villages and $3 \mathrm{~A}$ and $4 \mathrm{~A}$ scenic spots. Li Guo-Ying (2019) found in terms of the development of collective economy, through the deep integration of primary, secondary and tertiary industries, focus on building agricultural tourism economy, rural brand economy and activating collective assets to achieve the development of small town collective economy.

Due to the low level of knowledge and cultural quality of some farmers, the small-scale agricultural tourism integration projects they operate have problems such as chaotic management, unreasonable fees and poor service levels, which will inevitably affect the overall experience of tourists in the scenic spots and affect the brand building of tourist attractions. It is recommended that the government organize relevant training for such business entities. The training includes basic knowledge of agricultural tourism, etiquette, management and management. The training format is based on practical operations and uses language that is easily accepted by farmers. At the end of the training, examinations and examinations should be carried out to improve the efficiency and quality of the training. At the same time, corresponding knowledge manuals should be produced for review and use by the management subjects. Through the above methods, the management and service level of the business entities will be improved, the reputation resources of tourist attractions will be protected, and the agricultural tourism integration project will be developed in a long-term and sustainable manner.

\subsection{Increase Funding Support and Strengthen Infrastructure Construction}

We will formulate relevant policies for integrated development projects and financial support, and comprehensively promote the development of standards, scale and brands of integrated industries. We will set up investment and financing platforms and guide all sectors of society to participate in planning and construction, so that market players and local residents will become real players in industrial development. We will develop new ways of financing, explore financing channels such as industrial funds, equity-based crowdfunding, and PPP, and increase the introduction of private capital to promote the development of regional tourism through market-based mechanisms. Third party organizations are introduced to enable professional people to do professional work, and professional services such as financing, marketing, technology incubation and supply chain integration are provided to make the town a new platform for mass innovation.

We should vigorously strengthen the construction of infrastructure such as road traffic reconstruction, pipe network construction, commercial facilities, medical and health care, cultural and recreational facilities, so as to form a sys- 
tem and share resources with urban transportation, education and medical treatment. In the construction process, attention should be paid to the balance between development and protection, to make full use of existing equipment and facilities resources for upgrading and reconstruction, and to enhance the value connotation of the original construction.

\section{Conclusion}

In recent years, the coordinated development of agriculture and tourism has become a research hotspot. The practice of the integrated development of agriculture and tourism at home and abroad has proved that the integrated development of agriculture and tourism plays an important role in promoting farmers' income, agricultural efficiency and rural green. The main contribution of this paper is to start with the establishment of agricultural science and technology demonstration area in Jingzhou and promote the integrated development of agricultural tourism in Jingzhou from the aspect of characteristic agriculture. From the perspective of practice, when tourism scale is small, only through innovation (new products, new technologies, new consumption concepts, new plans, new economic growth points) can the integration of agriculture and tourism achieve high-quality development, and further promote the long-term development of ecological agriculture and ecological tourism. Hu \& Zhong (2019) use the data of national prefecture-level cities in 2010-2016 to empirically analyze the effect of the integration of agriculture and tourism supported by the government on the sustainable development of agriculture. This paper lacks research on quantitative indicators, so it is not scientific and persuasive. We will make relevant exploration in the next research.

\section{Acknowledgements}

This paper is supported by foundation for excellent young and middle-aged teachers in Yangtze University College of Arts and Sciences.

\section{Conflicts of Interest}

The authors declare no conflicts of interest regarding the publication of this paper.

\section{References}

Hu, P.-B., \& Zhong, Y.-P. (2019). The Mechanism of Improving Agricultural Eco-Efficiency by the Integration of Agriculture and Tourism Supported by the Government: Taking the National Leisure Agriculture and Rural Tourism Demonstration Counties as an Example. Chinese Rural Economy, 12, 85-104.

Li, G.-Y. (2019). The Path of Constructing a Modern Rural Industrial System from the Perspective of Rural Revitalization Strategy. Contemporary Economic Management, 10, 34-40.

Li, H.-J. (2018). Research on the Development Strategy of Lishui's Integration of Agriculture and Tourism to Promote Global Tourism Development. Hangzhou: Zhejiang 
Ocean University.

Lu, H.-X., \& Xu, J.-H. (2019). Research on the Development Path of Rural Characteristic Industry under the Rural Revitalization Strategy: Taking the Northern Jiangsu Province as an Example. Value Engineering, 21, 27-29.

Yue, F.-X. (2017). Study on the Tourism Development of Yibin Modern Agricultural Industrial Park from the Perspective of Agricultural Tourism Integration. Chengdu: Chengdu University of Technology.

Zhang, G. (2019). Research on the Integration and Development of Rural Tourism in Ethnic Minority Areas under the Rural Revitalization Strategy. Agricultural Economy, 4, 44-46.

Zhao, F., \& Liu, Y.-J. (2018). International Reference and Countermeasures for Three Industry Integration and Development in Rural Areas. Economic Review Journal, 9, 122-128.

Zhu, S.-B. (2017). The Practice and Thought of Sanhu Farm Promoting Agricultural Transformation and Development. China State Farm, 4, 30-31+68. 